\title{
REVIEW \\ Decline in Fertility of Paddy Soils Induced by Paddy Rice and Upland Soybean Rotation, and Measures against the Decline
}

\author{
Mizuhiko NISHIDA* \\ Lowland Farming Research Division, NARO Tohoku Agricultural Research Center \\ (Daisen, Akita 014-0102, Japan)
}

\begin{abstract}
Crop rotation between irrigated paddy rice (Oryza sativa L.) and upland soybean [Glycine max (L.) Merr.] (paddy-upland rotation) induces a decline in soil nitrogen $(\mathrm{N})$ fertility, as observed by available soil N. There was a significant negative correlation between the available soil $\mathrm{N}$ and the proportion of upland seasons to total crop seasons after the initiation of paddy-upland rotation (upland frequency). The decline in soil $\mathrm{N}$ fertility was alleviated by the application of organic materials. Soil total carbon also tended to decrease with an increase in upland frequency. Soil physical properties were affected by the paddy-upland rotation. As soil organic matter decomposed in paddy-upland rotation, the soil density increased with decreasing soil porosity. A suitable range of available soil $\mathrm{N}$ for paddy-upland rotation was identified between 80 and $200 \mathrm{mg} / \mathrm{kg}$, the same as for paddy rice. The keys to controlling soil $\mathrm{N}$ fertility in paddy-upland rotations are the upland frequency and application of organic materials. To sustain the available soil $\mathrm{N}$ over the minimum suitable level of $80 \mathrm{mg} / \mathrm{kg}$, the upland frequency should not exceed approximately $60 \%$ when only crop residues and no other organic materials are applied. The upland frequency can be increased by the repeated application of organic materials, thereby maintaining a higher level of available soil $\mathrm{N}$.
\end{abstract}

Discipline: Soils, fertilizers and plant nutrition

Additional key words: available soil nitrogen, organic materials, paddy-upland rotation, physical properties of soil, upland frequency

\section{Introduction}

The supply of rice in Japan has exceeded domestic demand for about 40 years, resulting in rice production adjustments. A typical adjustment is the rotation of paddy rice (Oryza sativa L.) in paddy fields and upland crops in drained paddy fields, which has been promoted to improve the self-sufficiency rates of upland crops. Soybean (Glycine $\max (\mathrm{L}$.) Merr.) is a major crop in this rotation sequence. The total area of soybean cultivation in drained paddy fields was 110,700 ha in 2014, accounting for about $30 \%$ of the area of upland crop cultivation in drained paddy fields (Takahashi et al. 2013, Ministry of Agriculture, Forestry and Fisheries 2014).

In leading soybean-producing countries, namely the USA and Brazil, the yield of soybean has increased to a level of almost $300 \mathrm{~g} / \mathrm{m}^{2}$, whereas the yield of soybean in Japan remains as low as about $150 \mathrm{~g} / \mathrm{m}^{2}$ (FAO 2014). The principal problem might be the vulnerability of soybean plants to wet injury in the ill-drained paddy fields of Japan.
The declining fertility of paddy soil under the ongoing crop rotation of paddy rice and upland soybean (paddy-upland rotation) has recently attracted attention as another reason for the stagnation of soybean yield. Declines in the fertility of paddy soils used for paddy-upland rotation were first reported in the early 1980s (Moroyu 1983, Nakano 1983). It was also observed that two to three years of paddy-upland rotation of both paddy rice and upland crops could maintain rice and soybean yields (Watanabe et al. 1985, Hanai 1987, Tsukuda 1990, Kitada et al. 1993). This two-to-three year rotation cycle of paddy rice and upland crops was generally accepted as suitable for maintaining crop productivity in paddy-upland rotations. Even though some studies still noted the declining fertility of paddy soils in paddy-upland rotations (Satou et al. 1993, Nagai et al. 1995), these results did not draw remarkable attention. In 2005, the research group of the Tohoku Agricultural Research Center (TARC), National Agriculture and Food Research Organization (NARO) reported in detail the declining soil fertility in paddy-upland rotations based on long-term field experi-

*Corresponding author: e-mail mizuhiko@affrc.go.jp

Received 22 April 2015; accepted 9 October 2015. 
ments (Sumida et al. 2005). After this landmark study, the decline in fertility of paddy soil was acknowledged as one of the main reasons for the stagnation of soybean yield. The research group of the NARO/TARC has conducted further extensive studies on the productivity of paddy soils in paddy-upland rotation (Nishida 2010, 2013, Nishida et al. 2013). The productivity of paddy soil is very important for food security in Japan. Here I review a series of studies on the productivity of paddy soils in paddy-upland rotation conducted at the NARO/TARC, including related studies in other areas.

\section{Decline in soil nitrogen fertility in paddy-upland rotation}

A decline in available soil nitrogen $(\mathrm{N})$, which was mineralized from air-dried soil under submerged conditions at $30^{\circ} \mathrm{C}$ for four weeks, was observed in a long-term field experiment conducted at the NARO/TARC (Fig. 1 (a)) (Sumida et al. 2005, Nishida 2013). This field experiment with paddy-upland rotation was initiated in 1990 (Table 1). A paddy field where only paddy rice had been cultivated with repeated application of cattle manure compost (CMC) until 1989 was divided into three plots in 1990. Three treatments representing paddy-upland rotation cycles were allocated to the plots (i.e., short-term upland rotation, mediumterm upland rotation, continuous paddy). In the short-term upland rotation, soybean and paddy rice were planted with a cycle of approximately one year for upland and two years for paddy (upland frequency: about 35\%). In the mediumterm upland rotation, a cycle of approximately three years for upland and one year for paddy was adopted (upland frequency: about $75 \%$ ). The upland frequency was defined as the ratio of the number of soybean cropping to total cropping year after the initiation of paddy-upland rotation. As a control, continuous paddy rice cropping was fixed in a continuous paddy. Each of the three treatments plots was divided into two parts, and organic material (i.e., rice straw) was applied at 0 or $600 \mathrm{~g} / \mathrm{m}^{2}$ after harvesting every autumn until 2001. The organic material was changed to livestock manure compost after 2003 , and applied at 0 or $1 \mathrm{~kg} / \mathrm{m}^{2}$ before the crop season every spring. The NARO/TARC is located in Daisen, Akita, in the Tohoku region of Japan (N39 $29^{\prime}, \mathrm{E} 140^{\circ} 30^{\prime}$, altitude $30 \mathrm{~m}$ ). Normal practice is for a single cropping each year in this region. The soil was classified as fine-textured gray lowland soil (Fluvisol, FAO 2006). Regardless of the upland frequency, available soil $\mathrm{N}$ declined in the paddy-upland rotation (Fig. 1 (a)). Because the initial available soil $\mathrm{N}$ was relatively high due to the repeated application of $\mathrm{CMC}$, available soil $\mathrm{N}$ declined even in the continuous paddy. The decrease in available soil $\mathrm{N}$ was greater in medium-term upland rotation than in short-term upland rotation. The decline in soil available $\mathrm{N}$ was alleviated by the application of organic materials. Total carbon (C) of soil also declined in paddy-upland rotation (Fig. 1 (b)). The available soil $\mathrm{N}$ might have become almost stable under each condition until nine years after the initiation of paddy-upland rotation. On the other hand, total soil
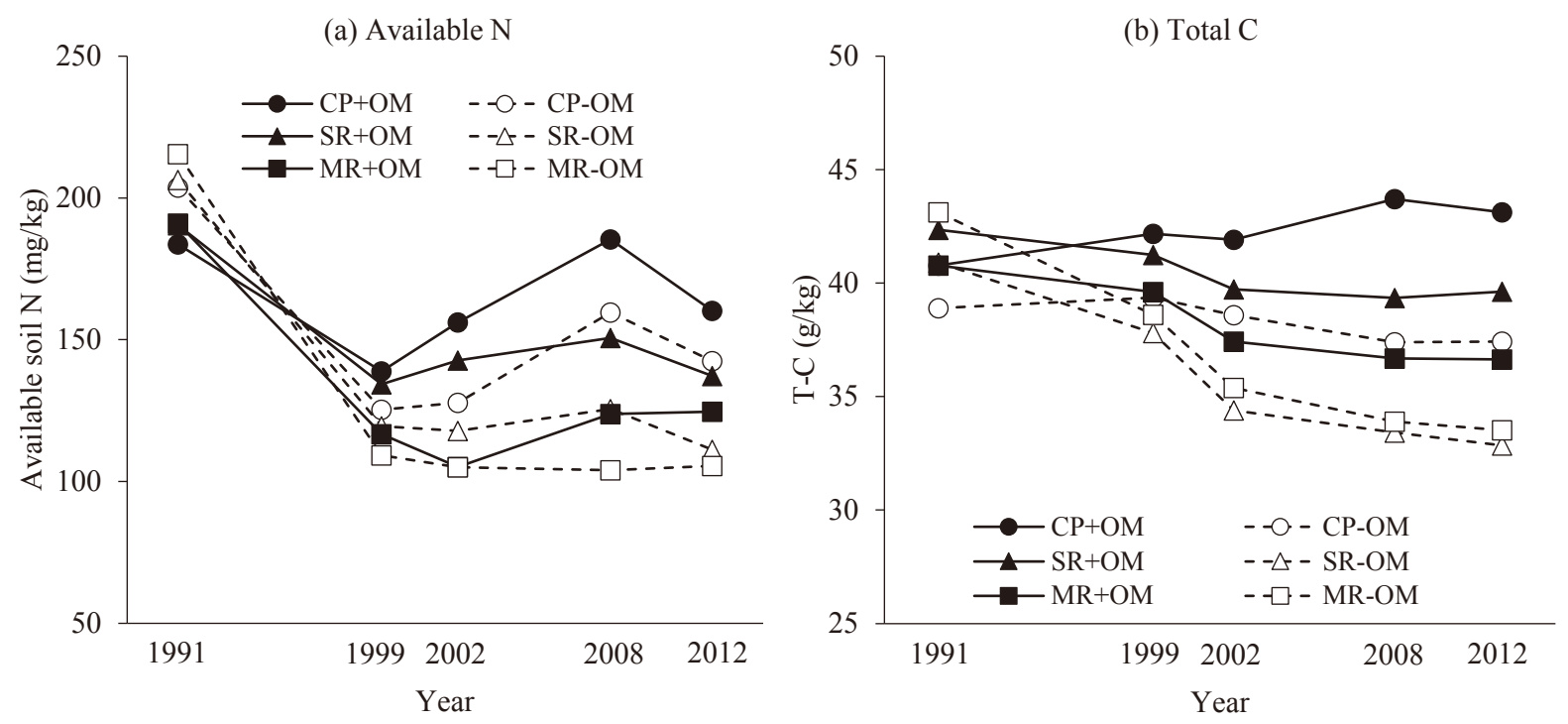

Fig. 1. Changes in available soil nitrogen (a) and total soil carbon (b) in the field experiment with paddy-upland rotation at the NARO/TARC

CP: continuous paddy; SR: short-term upland rotation; MR: medium-term upland rotation; +OM: organic materials applied; -OM: organic materials not applied; NARO/TARC: National Agriculture and Food Research Organization/Tohoku Agricultural Research Center. 
C tended to decrease for 22 years in paddy-upland rotation, especially without the application of organic materials.

Figure 2 (a) shows the relationship between the available soil $\mathrm{N}$ and upland frequency in four different farmers' fields where paddy-upland rotation had been carried out in Daisen, Akita (Nishida et al. 2013). Regardless of CMC application, a negative correlation was observed between the available soil $\mathrm{N}$ and upland frequency. It was demonstrated that soil $\mathrm{N}$ fertility, as represented by available soil $\mathrm{N}$, tended to decrease in paddy-upland rotations under different management practices in this region, and that the decrease in soil $\mathrm{N}$ fertility was quantitatively associated with the upland frequency. The available soil $\mathrm{N}$ was maintained approximately $60 \mathrm{mg} / \mathrm{kg}$ higher in soils under repeated $\mathrm{CMC}$ application at the rate of $2-3 \mathrm{~kg} / \mathrm{m}^{2}$ than in soils without $\mathrm{CMC}$ application, where only crop residues were returned. Total $\mathrm{C}$ of soil also declined in paddy-upland rotation (Fig. 2 (b)). These results indicate that soil organic matter decomposes in paddy-upland rotation, leading to a decline in available soil $\mathrm{N}$.

Recently, declines in the $\mathrm{N}$ fertility of paddy soils were observed in other areas, such as fine-textured gray lowland soil in Niigata, Hokuriku region (Hattori et al. 2013), coarse-textured gray lowland soil in Toyama, Hokuriku region (Hirokawa et al. 2011), fine-textured gray lowland soil in Kyoto, Kinki region (Matsumoto \& Yoshikawa 2010), and fine-textured gray lowland soil in Fukuoka, Kyushu region (Odahara et al. 2012).

Under the oxidative conditions in upland fields, the decomposition of soil organic matter is promoted compared

Table 1. Design of the long-term field experiment with paddy-upland rotation at the NARO Tohoku Agricultural Research Center



R: Rice; S: Soybean.

Rice straw was repeatedly applied at 0 or $600 \mathrm{~g} / \mathrm{m}^{2}$ every autumn until 2001 . Livestock manure compost was repeatedly applied at 0 or $1 \mathrm{~kg} / \mathrm{m}^{2}$ every spring from 2003 .

(a) Available $\mathrm{N}$

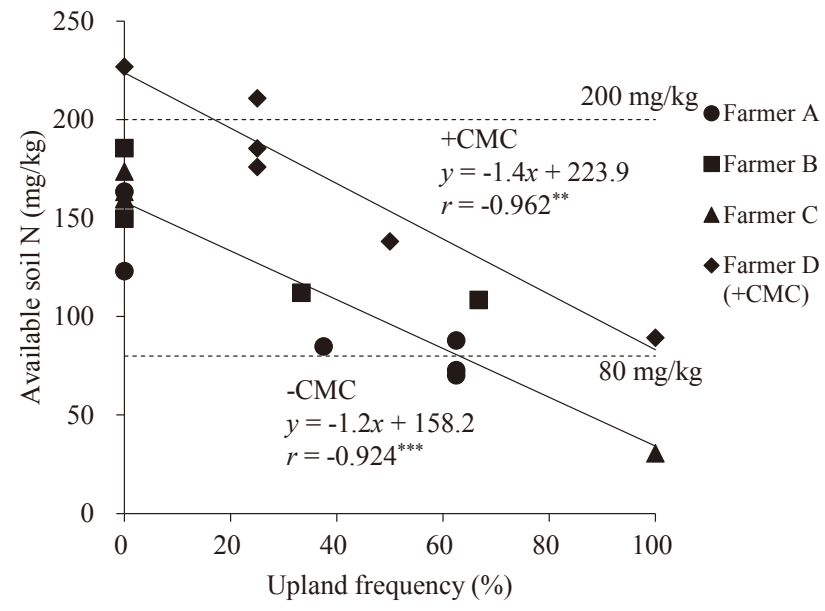

(b) Total C

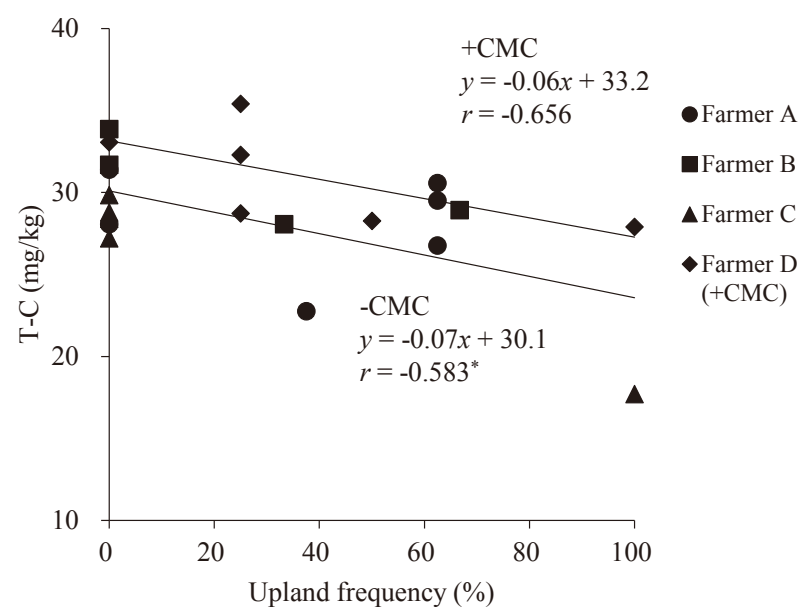

Fig. 2. Relationship between upland frequency and available soil nitrogen (a), and total soil carbon (b) in four different farmers' fields

$* * * P<0.001, * * P<0.01, * P<0.05$. + CMC: cattle manure compost applied; -CMC: cattle manure compost not applied. Broken lines indicate the minimum $(80 \mathrm{mg} / \mathrm{kg})$ and maximum $(200 \mathrm{mg} / \mathrm{kg})$ values of suitable concentrations of available soil N in paddy field (Ministry of Agriculture, Forestry and Fisheries, 2009). 
with the reductive conditions of submerged paddy fields (Tsutsuki 2001). Land use change from paddy rice cultivation to upland crop cultivation has been demonstrated to change the soil $\mathrm{C}$ budget from positive to negative, due mainly to decreasing net carbon dioxide $\left(\mathrm{CO}_{2}\right)$ absorption (Nishimura et al. 2008). The decomposition of soil organic matter might be accelerated especially under soybean cultivation. Vanotti \& Bundy (1995) suggested that soybean cultivation stimulated soil microorganisms, which led to enhanced soil $\mathrm{N}$ mineralization and a large $\mathrm{N}$ uptake in the first year of corn (Zea mays L.) cultivation following soybean, resulting in a depletion of readily available soil $\mathrm{N}$ in the second year after soybean cultivation. In another study, soybean showed a greater rhizosphere priming effect on total soil $\mathrm{C}$ efflux as compared with wheat (Triticum aestivum L.) (Cheng et al. 2003). Annual $\mathrm{N}$ budgets in an upland soybean field converted from a paddy rice field on gray lowland soil were negative, ranging from -14.2 to $-6.4 \mathrm{~g} \mathrm{~N} / \mathrm{m}^{2}$, because a large quantity of $\mathrm{N}$ was removed from the field with harvested soybeans (Takakai et al. 2010). In contrast, the $\mathrm{N}$ budgets in paddy rice fields (rice cultivation) have been shown to be even or positive (App et al. 1984, Kyuma 2004). The negative $\mathrm{N}$ budget in upland soybean cultivation might be one reason for the decrease in soil $\mathrm{N}$ fertility in paddy-upland rotation.

\section{Changes in other soil properties in paddy-upland rotation}

The physical properties of soil are affected by paddyupland rotation. As soil organic matter decomposes in paddy-upland rotation, soil density increases with decreas- ing soil porosity. Solid phase ratios in the soil of short-term upland rotation were higher than those in the continuous paddy (Fig. 3 (a)). Similarly, solid phase ratios in the soil of medium-term upland rotation were higher than those in short-term upland rotation (Fig. 3 (b)). For any upland frequency tested, the application of organic materials decreased the solid phase ratio and increased the gaseous phase ratio. The application of organic materials could thus alleviate the densification of paddy soil in paddy-upland rotation. Odahara et al. (2012) observed positive correlations between the upland frequency and solid phase ratio of soil, and bulk density of soil, respectively, in fields with paddy-upland rotation in Fukuoka. They also observed a negative correlation between the upland frequency and gaseous phase ratio of the soil.

The application of soil amendments for soybean cultivation can improve some of the chemical properties of soil. A positive correlation was observed between the upland frequency and soil $\mathrm{pH}$ in fields where magnesium lime was applied for every soybean crop season (Nishida et al. 2013). The $\mathrm{pH}$ of soils in continuous paddy rice fields was below the optimal range of 6.0 to 6.5 , as identified by the Ministry of Agriculture, Forestry and Fisheries (2009). The pH values of soil in paddy-upland rotation were higher and closer to the optimal $\mathrm{pH}$ range than those in the continuous paddy rice fields. Exchangeable calcium and magnesium were also improved by paddy-upland rotation due to the application of magnesium lime for soybean cultivation. Odahara et al. (2012) observed a positive correlation between the upland frequency and soil $\mathrm{pH}$ in the fields with paddy-upland rotation in Fukuoka. (a) After rice cultivation (2004)

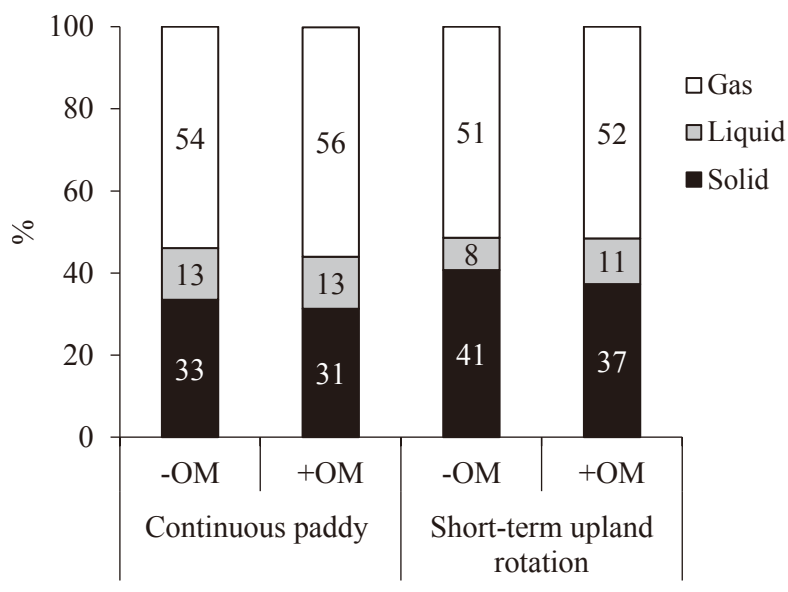

(b) After soybean cultivation (2005)

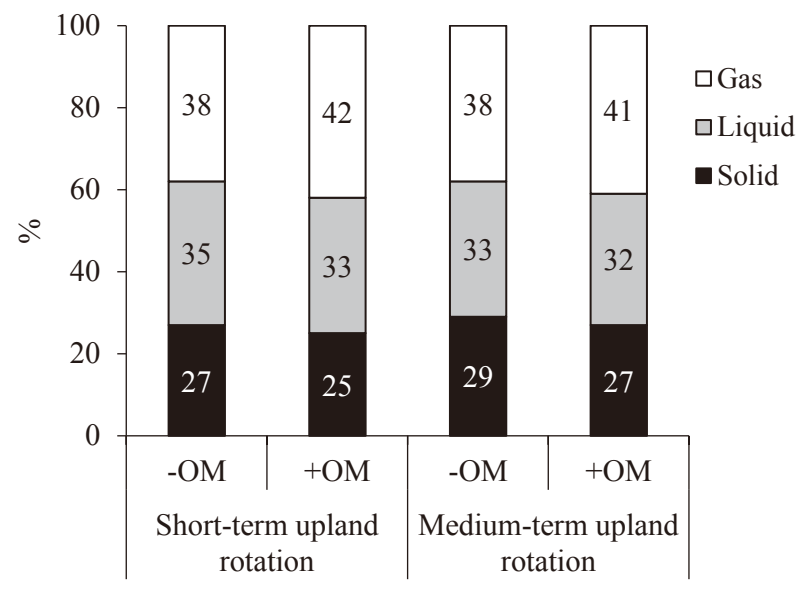

Fig. 3. Ratios of three phases in soils in the field experiment with paddy-upland rotation at the NARO/TARC +OM: organic materials applied; -OM: organic materials not applied; NARO/TARC: National Agriculture and Food Research Organization/Tohoku Agricultural Research Center. 


\section{Productivity of crops in paddy-upland rotation}

A decline in soil $\mathrm{N}$ fertility induces a decrease in soybean yield. Yield data on paddy-upland rotation were comprehensively collected from the experimental plots at the NARO/TARC, irrespective of fertilizer management, where available soil $\mathrm{N}$ was measured during each year from 1991 to 2009 (Fig. 4) (Nishida 2010). The soybean yield decreased as the available soil $\mathrm{N}$ decreased. A significant relationship was found between the available soil $\mathrm{N}$ and soybean yield. According to the quadratic equation, when target yields were set to $300 \mathrm{~g} / \mathrm{m}^{2}$ for soybean and $600 \mathrm{~g} / \mathrm{m}^{2}$ for rice, the available soil $\mathrm{N}$ needs to exceed $80 \mathrm{mg} / \mathrm{kg}$ to obtain the target soybean yield. A significant relationship was not found between the available soil $\mathrm{N}$ and rice yield in paddy-upland rotation. The rice yield decreased because of lodging when the available soil $\mathrm{N}$ exceeded $200 \mathrm{mg} / \mathrm{kg}$, suggesting that available soil $\mathrm{N}$ should be lower than $200 \mathrm{mg} / \mathrm{kg}$ in paddy-upland rotation. The rice yield tended to be over $600 \mathrm{~g} / \mathrm{m}^{2}$ when the available soil $\mathrm{N}$ ranged from 80 to $200 \mathrm{mg} / \mathrm{kg}$. The suitable range of available soil $\mathrm{N}$ for paddy-upland rotation is 80 to $200 \mathrm{mg} / \mathrm{kg}$, which corresponds with the optimal range of soil available $\mathrm{N}$ identified by the Ministry of Agriculture, Forestry and Fisheries (2009) for paddy rice.

Decreases in the soybean yield in paddy-upland rotation were also observed in other areas. In gray lowland soil at Toyama, the soybean yield decreased as the upland frequency increased (Hirokawa et al. 2011). In gray lowland soil at Niigata, paddy-upland rotation induced a decline in mineralizable $\mathrm{N}$ after the flowering stage. This reduced the number of pods and the growth of beans in each pod, resulting in a decreased soybean yield (Hattori et al. 2013). In gray lowland soil at Fukuoka, paddy-upland rotation affected the physical properties of soil, also leading to a decreased soybean yield. Significant negative correlations were observed between the soybean yield and the rate of solid phase, rate of liquid phase, and bulk density in the soil, respectively. Conversely, a positive correlation was found between the soybean yield and the rate of gaseous phase in the soil (Odahara et al. 2012). In gray lowland soil in Kyoto, a remarkable decrease in soybean yield was observed in fields where soybean was repeatedly cultivated for four years or more. The main cause of these decreases in soybean yield was considered to be the decrease in symbiotic N fixation (Matsumoto \& Yoshikawa 2010).

\section{Measures against the declines in soil nitrogen fertility under paddy-upland rotation}

The keys to controlling soil $\mathrm{N}$ fertility in paddyupland rotation are the balance of paddy rice and soybean cultivations, namely the upland frequency and application of organic materials. As stated above, the suitable range of available soil $\mathrm{N}$ for paddy-upland rotation is $80-200 \mathrm{mg} / \mathrm{kg}$ (Nishida 2010). Figure 2 (a) clearly shows the management strategies required to maintain the minimum level of available soil $\mathrm{N}$ for paddy-upland rotation. According to the regression line, in fields without the application of organic materials except crop residues, available soil $\mathrm{N}$ was lower than $80 \mathrm{mg} / \mathrm{kg}$ when the upland frequency was higher than approximately $60 \%$. The upland frequency must be (a) Soybean

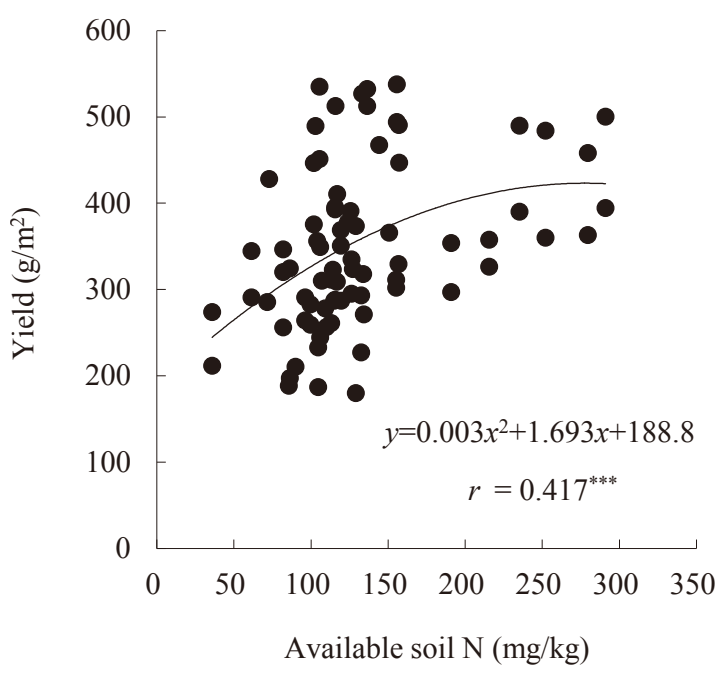

(b) Rice

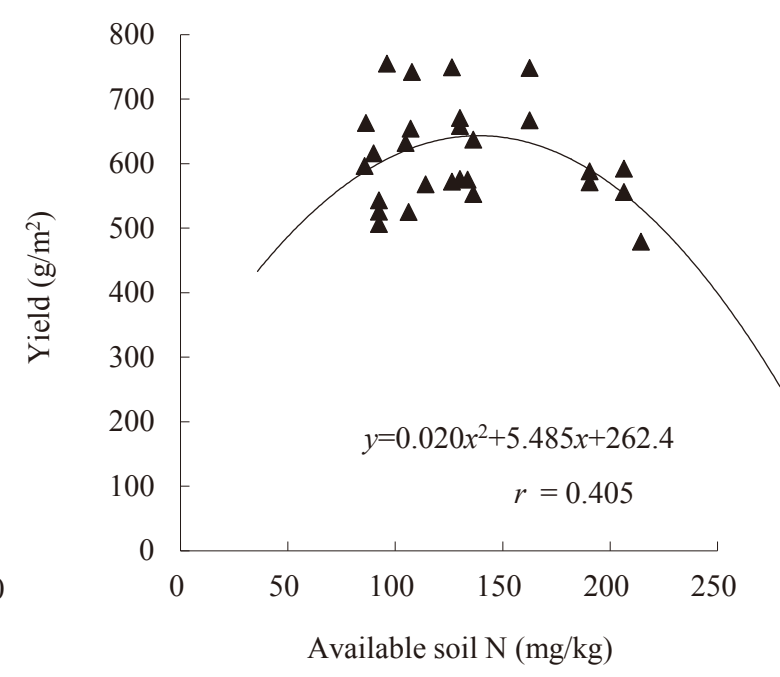

Fig. 4. Relationship between available soil $\mathrm{N}$ and yield of soybean (a), and yield of rice (b) in the field experiment with paddyupland rotation at the NARO/TARC

***P<0.001. NARO/TARC: National Agriculture and Food Research Organization/Tohoku Agricultural Research Center. 
lower than $60 \%$ in order to maintain the minimum level of available soil $\mathrm{N}(80 \mathrm{mg} / \mathrm{kg})$ in cases without the application of organic materials except crop residues. Under repeated application of $\mathrm{CMC}$ at the rate of $2-3 \mathrm{~kg} / \mathrm{m}^{2}$, available soil $\mathrm{N}$ could be maintained at more than $80 \mathrm{mg} / \mathrm{kg}$, even with an upland frequency of $100 \%$. With repeated application of CMC to paddy rice and soybean cultivations conducted at the same frequency (upland frequency: 50\%), available soil $\mathrm{N}$ could be maintained at the same level as that in continuous paddy fields without the application of organic materials except crop residues (upland frequency: $0 \%$ ). Soybean cultivation could be conducted more frequently in fields with the application of CMC than in fields without the application of organic materials, as the available soil $\mathrm{N}$ would be maintained within the suitable range. Hirokawa et al. (2011) reported that in order to maintain available soil $\mathrm{N}$ at the same level as in a continuous paddy field, CMC must be applied twice in a three-year period during which soybean was cultivated once (upland frequency: $33 \%$ ). This result is similar to our findings shown in Fig. 2 (a).

From the field experiment of long-term upland con- version with the application of rice straw compost (RSC) conducted at the NARO/TARC (Table 2), another strategy to manage available soil $\mathrm{N}$ was discovered (Nishida 2010). The decrement in available soil $\mathrm{N}$ during the period of 18year upland (soybean) conversion with repeated application of RSC at the rate of $2 \mathrm{~kg} / \mathrm{m}^{2}$, and the increment in available soil $\mathrm{N}$ for the same duration of continuous paddy rice with repeated application of RSC at the same rate were evaluated. The decrements in available soil $\mathrm{N}$ for two years of soybean cultivation almost corresponded to the increments in available soil $\mathrm{N}$ for three years of paddy rice cultivation (Fig. 5). These results suggested that by conducting paddyupland rotation with the combination of two-year soybean and three-year rice under repeated application of RSC at the rate of $2 \mathrm{~kg} / \mathrm{m}^{2}$, the available soil $\mathrm{N}$ could be maintained. This was verified by the field experiment. Paddy-upland rotation with a cycle of two-year soybean and three-year rice under repeated application of RSC at the rate of $2 \mathrm{~kg} / \mathrm{m}^{2}$ was conducted twice (10 years, Table 2 ). The available soil $\mathrm{N}$ after paddy-upland rotation was similar to that before paddy-upland rotation (Fig. 6).

Table 2. Design of the field experiment with long-term upland conversion at the NARO Tohoku Agricultural Research Center

\begin{tabular}{lcccccc}
\hline \hline Year & $-' 81$ & $1982-1999$ & $2000-2002$ & $2003-2004$ & $2005-2007$ & $2008-2009$ \\
\hline Long-term upland conversion & $\mathrm{R}$ & $\mathrm{S} \times 18$ & $\mathrm{R} \times 3$ & $\mathrm{~S} \times 2$ & $\mathrm{R} \times 3$ & $\mathrm{~S} \times 2$ \\
\hline Continuous paddy & $\mathrm{R}$ & & $\mathrm{R} \times 28$ & & \\
\hline
\end{tabular}

R: Rice; S: Soybean.

Rice straw compost was repeatedly appliet at 0 or $2 \mathrm{~kg} / \mathrm{m}^{2}$ every spring.

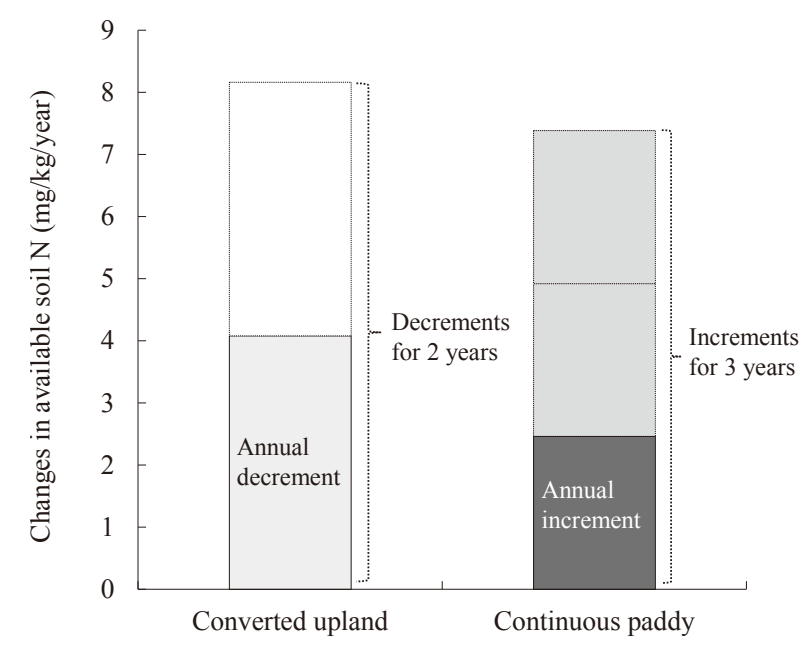

Fig. 5. Annual changes in available nitrogen $(\mathrm{N})$ in 18-year upland (soybean) converted field and continuous paddy field with repeated application of rice straw compost at the rate of $2 \mathrm{~kg} / \mathrm{m}^{2}$

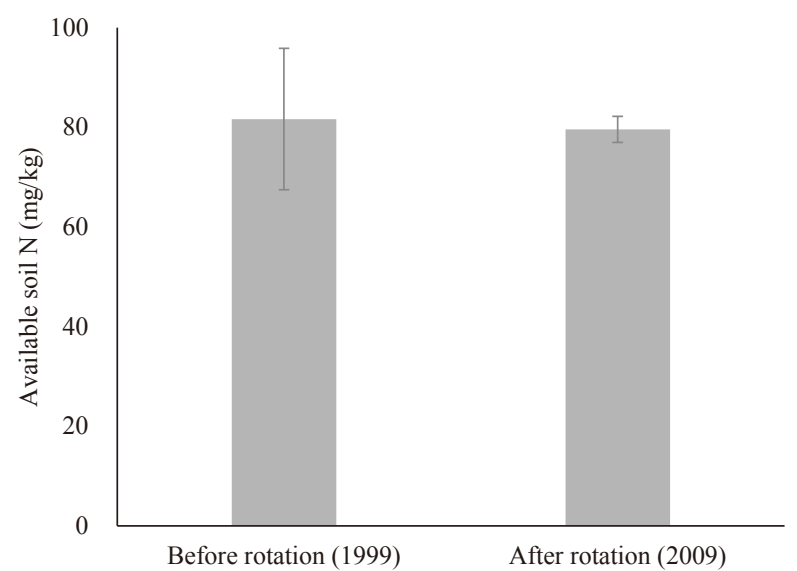

Fig. 6. Available soil $\mathrm{N}$ before and after paddy-upland rotation with two cycles of 3-year paddy rice and 2-year soybean, and repeated application of rice straw compost at the rate of $2 \mathrm{~kg} / \mathrm{m}^{2}$

Error bars indicate SD. 
Green manure also shows potential for maintaining soil $\mathrm{N}$ fertility in paddy-upland rotations. Some studies reported the effects of green manure on soybean plants and soil N fertility (Sato 2010, Hirokawa et al. 2011). However, the long-term effects of green manure on soil $\mathrm{N}$ fertility in paddy-upland rotations have not been confirmed.

\section{Issues and perspectives}

There are still many issues that should be addressed in this research area. The relationships between soil fertility and soil management (as shown in Fig. 2) should be clarified in terms of regionality and soil type. Figure 2 clearly shows the effect of $\mathrm{CMC}$ on soil $\mathrm{N}$ fertility; however, the quantitative effects of other organic materials on soil $\mathrm{N}$ fertility remain unknown. For instance, the effects of poultry manure compost and swine manure compost on soil $\mathrm{N}$ fertility in paddy-upland rotation have yet to be elucidated. It was reported that different versions of the Rothamsted Carbon model could simulate soil carbon dynamics in paddyupland rotations (Shirato et al. 2011). The development of a dynamic model of available soil $\mathrm{N}$ in paddy-upland rotation would greatly improve the understanding and management of soil $\mathrm{N}$ fertility. In regions where manure from livestock is unavailable, technologies to improve soil fertility should be developed using locally available organic resources, including green manure. At present, laborsaving technologies are urgently needed in paddy-upland rotation systems in landextensive farming. Soil fertility management practices must also be applicable to laborsaving farming systems.

\section{References}

App, A. et al. (1984) Estimation of the nitrogen balance for irrigated rice and the contribution of phototropic nitrogen fixation. Field Crop Res., 9, 17-27.

Cheng, W. et al. (2003) Rhizosphere effects on decomposition: Controls of plant species, phenology, and fertilization. Soil Sci. Soc. Am. J., 67, 1418-1427.

FAO (Food and Agriculture Organization of the United Nations) (2006) World Reference Base for Soil Resources 2006, FAO, Rome.

FAO (Food and Agriculture Organization of the United Nations) (2014) FAOSTAT. http://faostat3.fao.org/home/E.

Hanai, Y. (1987) Cropping systems in paddy field for multiple uses. Norin suisan gijutsu kenkyu journal (Res. J. Food Agric.), 10, 28-32 [In Japanese].

Hattori, M. et al. (2013) Effect of continuous cropping and longterm paddy-upland rotation on yield reduction of soybean in Niigata prefecture. Nippon sakumotsu gakkai kiji (Jpn. J. Crop Sci.), 82, 11-17 [In Japanese with English summary].

Hirokawa, T. et al. (2011) Declines in soil nitrogen fertility after rotation of medium and coarse-textured gray lowland soil and restoration methods with green manure and cattle manure compost. Toyama-ken norin-suisan gijutsu center nogyo kenkyusho hokoku (Bull. Agr. Res. Inst., Toyama Pref. Agr., For. Fish Res. Ctr.), 2, 11-26 [In Japanese with English summary].

Kitada, K. et al. (1993) Changes in soil nutrients affected by rotation of upland and paddy crop in gray lowland soil and search for the most suitable term of rotation. Nippon dojohiryogaku zasshi (Jpn. J. Soil Sci. Plant Nutr.), 64, 154-160 [In Japanese with English summary].

Kyuma, K. (2004) Paddy Soil Science. Kyoto University Press, Kyoto, and Trans Pacific Press, Melbourne, pp.280.

Matsumoto, S. \& Yoshikawa, M. (2010) Influence of continuous cropping on yield of black soybean and chemical properties of soils in the field converted from paddy. Nippon sakumotsu gakkai kiji (Jpn. J. Crop Sci.), 79, 268-274 [In Japanese with English summary].

Ministry of Agriculture, Forestry and Fisheries (2009) Chiryoku zoshin kihon shisin (Basic direction for improvement of soil fertility. http://www.maff.go.jp/j/seisan/kankyo/hozen_type/ h_dozyo/pdf/chi4.pdf [In Japanese].

Ministry of Agriculture, Forestry and Fisheries (2014) Statistics of Agriculture, Forestry and Fisheries. http://www.maff. go.jp/j/tokei/kouhyou/sakumotu/menseki/pdf/sakutuke_daizu_14.pdf [In Japanese].

Moroyu, H. (1983) Change of physical and chemical properties of paddy soils under the cultivation of upland crops. Nippon dojo-hiryogaku zasshi (Jpn J. Soil Sci. Plant Nutr.), 54, 434441 [In Japanese].

Nagai, H. et al. (1995) Changes in the physical and chemical properties of gray lowland soils on paddy-upland rotation field. Kyushu nogyo kenkyu (Kyushu Agric. Res.), 57, 69 [In Japanese].

Nakano, K. (1983) Studies on the soil improvement for rotational field of clayey soil by applications of amendment materials. Hokuriku nogyo shikenjo hokoku (Bull. Hokuriku Natl. Agric. Exp. Stn.), 25, 87-108 [In Japanese with English summary].

Nishida, M. (2010) Changes in nitrogen fertility of soils in paddy-upland rotation fields and strategies for its fertility management. In Denpatarinkandojo no hiyokudo to kanri (Fertility and management of soil in paddy-upland rotation fields in Japan - factors of fertility change and approaches for its control), eds. Toriyama, K. et al., Hakuyusha, Tokyo, Japan, 27-52 [In Japanese].

Nishida, M. (2013) Changes in the fertility of paddy soils under paddy-upland rotation in the cool climate region of Japan and countermeasures for the changes. Proceedings of NARO Symposium, Paddy-upland rotation and soil fertility. 10-15 [In Japanese].

Nishida, M. et al. (2013) Status of paddy soils as affected by paddy rice and upland soybean rotation in northeast Japan, with special reference to nitrogen fertility. Soil Sci. Plant 
Nutr., 59, 208-217.

Nishimura, S. et al. (2008) Effect of land use change from paddy rice cultivation to upland crop cultivation on soil carbon budget of a cropland in Japan. Agric. Ecosyst. Environ., 125, 9-20.

Odahara, K. et al. (2012) The soil fertility status and soybean productivity in paddy-upland rotation fields in Japan's Chikugo River basin. Nippon dojo-hiryogaku zasshi (Jpn J. Soil Sci. Plant Nutr.), 83, 405-411 [In Japanese with English summary].

Sato, T. (2010) Soil fertility management using green manure for paddy-upland rotation fields. In Denpatarinkandojo no hiyokudo to kanri (Fertility and management of soil in paddy-upland rotation fields in Japan - factors of fertility change and approaches for its control), eds. Toriyama, K. et al., Hakuyusha, Tokyo, Japan, 165-192 [In Japanese].

Satou, F. et al. (1993) Change of physical and chemical properties of paddy soils under rotated cultivation with special reference to the soil fertility and physical properties. Tohoku nogyo kenkyu (Tohoku Agric. Res.), 46, 77-78 [In Japanese].

Shirato, Y. et al. (2011) Using different versions of the Rothamsted Carbon model to simulate soil carbon in long-term experimental plots subjected to paddy-upland rotation in Japan. Soil Sci. Plant Nutr., 57, 597-606.

Sumida, H. et al. (2005) Depletion of soil fertility and crop productivity in succession of paddy rice-soybean rotation.
Tohoku nogyo kenkyu center kenkyu hokoku (Bull. Natl. Agric. Res. Cent. Tohoku Reg.), 103, 39-52 [In Japanese with English summary].

Takahashi, T. et al. (2013) A new framework for study of irrigated paddy rice and upland crops rotation farming and its relation to soil and plant nutrition science. 1. Advances and perspectives in irrigated paddy rice and upland crops rotation farming. Nippon dojo-hiryogaku zasshi (Jpn J. Soil Sci. Plant Nutr.), 84, 202-207 [In Japanese].

Takakai, F. et al. (2010) Effects of preceding compost application on the nitrogen budget in an upland soybean field converted from a rice paddy field on gray lowland soil in Akita, Japan. Soil Sci. Plant Nutr., 56, 760-772.

Tsukuda, K. (1990) Paddy-upland rotation cycle setup: Introduction of experiments in Kanto-Tokai district. Nogyo oyobi engei (Agric. Hortic.), 65, 385-388 [In Japanese].

Tsutsuki, K. (2001) Soil organic matter. In Dojogaku gairon (Soil science), eds. Inubushi, K. \& Anzai, T., Asakura Shoten, Tokyo, 51-59 [In Japanese].

Vanotti. M.B. \& Bundy, L.G. (1995) Soybean effects on soil nitrogen availability in crop rotations. Agron. J., 87, 676-680.

Watanabe, K. et al. (1985) The stable production of good quality rice and soybean at paddy-upland rotation cultivation. Yamagataken nogyo shikenjo hokoku (Bull. Yamagata Agric. Exp. Stn.), 20, 1-22 [In Japanese with English summary]. 